\title{
Periodontitis in Patients with Cirrhosis at Chandka Medical College Hospital and Bibi Aseefa Dental College Hospital Larkana
}

\author{
Almas Rahoojo', Samreen Naz², Wahid Murad Dahri³, Mansoor Ahmed Rahoojo4, Arhama Sarwaich ${ }^{5}$, Sarwaich Ali Channa ${ }^{6}$ \\ 1,3,4Department of Oral and Maxillofacial Surgery, Bibi Aseefa Dental Shaheed Mohtarma Benazir Bhutto Medical University College Larkana-Pakistan, 2,5Department of Oral and \\ Maxillofacial Surgery, Bhitai Dental \& Medical College Mirpur-Khas-Pakistan, ${ }^{6}$ Department of Oral Pathology, Isra Dental \& Medical College Hyderabad-Pakistan
}

\begin{abstract}
Background: In the patients of cirrhosis oral health id generally poor and may lead oral infections. Periodontal disease is an infection of structures in mouth that surround the teeth, which is linked with several systemic diseases, including cirrhosis. Objective: To determine the frequency of Periodontitis in patients with cirrhosis at Chandka medical college hospital and Bibi Asifa dental college hospital Larkana. Study Design: crosssectional study. Settings: Department of Medicine and Department of Periodontology at Chandka Medical College Hospital and Bibi Asifa dental college Hospital Larkana Pakistan. Duration: Six months from 01-08-2019 to 31-01-2020. Methodology: All the diagnosed patients of liver cirrhosis of based on either elastography and/or clinical, biochemical, and ultrasonic findings having, age $>18$ years having and either of gender were included in the study. Severity of liver cirrhosis was assessed by Child-Pugh classification taking help of gastroenterologists. Periodontitis was defined as progressive chronic inflammatory destruction of connective tissue of tooth and surrounding structures eventually leads to tooth loss. Data was collected via study proforma and analyzed by using SPSS software version 20.0. Results: Total 100 cirrhosis patients were studied; patients mean age was $46.10 \pm 9.01$ years and average of disease duration was $2.10 \pm 1.7$ years. Males were most common $62.0 \%$. Plaque was seen almost in all cases $98.0 \%$. Most of the cases had moderate and severe periodontitis $36.0 \%$ and $35.0 \%$ respectively $26.0 \%$ had mild periodontitis. Moderate and severe periodontitis were significantly high in patients having age more than 40 years, female gender and having child Pugh class II and III, ( $p=0.001)$. However, there was no significant association between severity of periodontitis and duration of cirrhosis. Conclusion: In the observation of this study the periodontitis rate was higher in patients of cirrhosis and it was significantly linked to child Pugh class II and III. Oral health status should be assessed maintained among patients of cirrhosis.
\end{abstract}

Keywords: Liver cirrhosis, Periodontitis, Severity.

Corresponding Author Submitted for Publication: 13-03-2020 Accepted for Publication: 21-09-2020

Dr. Almas Rahoojo, Assistant Professor, Department of Oral and Maxillofacial Surgery, Bibi Aseefa Dental (SMBBMU) College Larkana-Pakistan Email: almasrahoojo@yahoo.com

Citation: Rahoojo A, Naz S, Dahri WM, Rahoojo MA, Sarwaich A, Channa SA. Periodontitis in Patients with Cirrhosis. APMC 2020;14(3):259-62. DOI: 10.29054/APMC/2020.891

\section{INTRODUCTION}

Periodontitis is a multifactorial etiology involving inflammatory disease, which affects the underlying teeth tissues and is marked by deepening periodontal pockets, gradual loss of alveolar bone and attachment of connective tissue across the teeth, progressing gradually towards tooth loss. Periodontitis, if unresolved, can lead to irritation, pain, poor mastication, and loss of the tooth. 1,2

Periodontal disorder is a widespread chronic condition, with an approximate incidence from $10 \%$ to $60 \%$ in adults, is referred to as periodontitis (irreversible) or gingivitis (reversible). Gingivitis can evolve into periodontitis, with inflammatory response of underlying soft tissues of gingiva or tooth, over time. it may be diagnosed through clinical assessment using periodontal probe to assess the clinical attachment loss and pocket depth in conjunction with radiographic assessment. ${ }^{2}$ Periodontal disease, even with slight periodontal tissue chronic inflammation, is correlated to malnutrition, systemic conditions including cardiovascular disorder, cirrhosis and type II DM, chronic renal disease, and also preterm low birth weight in infants. ${ }^{1-5}$ Cirrhosis, a final stage of hepatic disorder, is among the most prevalent factors of mortality and morbidity globally. Cirrhosis, following many years or even decades of inflammatory response and fibrosis, leads to hepatic nodular change. It clinically has two stages, compensated and decompensated (oesophageal varices, malnutrition symptoms oedema, ascites, jaundice and coagulation abnormalities). ${ }^{6}$

Across the Us alone, the disorder has an annual mortality rate of around $13.2 \%$ and it is the twelfth major factor of death. Cirrhosis may be caused by different etiologies including viral hepatitis (hepatitis B and hepatitis C), alcoholic related liver disease (ARLD) and nonalcoholic steato-hepatitis/nonalcoholic fatty liver disease (NASH/NAFLD) being among the most common. Viral hepatitis is presently the major cause of cirrhosis, globally. ${ }^{7}$

As a result of hepatic failure, hepatic cirrhosis cases have raised serum cytokine concentrations, which are likely to be involved with destructive phase of periodontal disorder by enhancing metalloproteinase and collagenase activity. So, with the consideration of the oral cavity, changes in immune system and elevated levels of cytokines can be involved in significant periodontal breakdown. Oral health has been found to be usually poor among patients having cirrhosis and chronic periodontal disease (gingival bleeding, gingivitis) is a common finding. The risk factors and incidence for periodontitis among cirrhotic patients are investigated individually. 1,2,4,8 
A cross sectional study conducted in Denmark over 145 patients of cirrhosis found $46 \%$ cases of severe periodontitis, $39 \%$ cases of moderate periodontitis, and just $15 \%$ cases of either no periodontitis or mild periodontitis. Periodontitis has been found to be extremely common among cirrhosis patients in all etiologies. ${ }^{1}$

In some studies, reported greater frequency of severe gingivitis in addition to a higher incidence of oral lesions among hepatic disorder patients, indicating the advancement of hepatic dysfunction. 3,5 On other hand it is stated that, in cirrhosis, the estimated incidence of periodontal disorder is controversial. ${ }^{2}$

At, Chandka Medical College Hospital Larkana, has a huge population of hepatic cirrhosis patients becuase of traditional causes and mostly because of viral Hepatitis ( $B$ and $C$ ). A hepatic cirrhosis study will therefore be of critical interest and usefulness in this region. Bacterial infections are widespread and raise mortality and morbidity, despite modern medical treatments that have significantly enhanced the capacity to treat and prevent complications of cirrhosis. Infection in oral cavity mostly leads to localized disease; however systemic disease and bacteremia can also emerge from oral infections. It would be of great significance to validate oral condition as an independent risk factor for adverse cirrhotic outcomes, since this condition is both treatable and preventable. However, in our system, dental disorders and complaints are being overlooked, which renders the strategies of successful management controversial. This study thus aimed to assess the frequency of periodontitis in cirrhosis at Chandka medical college hospital and Bibi Asifa dental college hospital larkana that will establish directions for future research.

\section{METHODOLOGY}

Study Design: Cross-sectional study.

Settings: Department of Medicine and Department of Periodontology at Chandka Medical College Hospital and Bibi Asifa Dental College Hospital Larkana Pakistan.

Duration: Six months from 01-08-2019 to 31-01-2020.

Sample Technique: Non probability consecutive sampling.

Sample Size: Study consists of 100 patients of cirrhosis.

Inclusion Criteria: All the diagnosed patients of hepatic cirrhosis as per either elastography and/or clinical, ultrasonic, and biochemical findings having, age $>18$ years having and either of gender were included in the study.

Exclusion Criteria: All the smoker and wearing dental braces patients and those were on cardiac treatment, diuretic therapy, on immunosuppressive drugs and on antibiotic therapy with in last 6 months were excluded.

Data Collection Procedure: Informed consent was taken from each patient. Patients were interviewed regarding age, smoking status, any comorbidity, and oral care practices (such as frequencies of dental visits and tooth brushing). Severity of hepatic cirrhosis was evaluated by Child-Pugh classification taking help of gastroenterologists. Periodontitis was defined as progressive chronic inflammatory destruction of connective tissue of tooth and surrounding structures eventually leads to tooth loss. ${ }^{2}$ Periodontitis was classified according to previous publish studies; 9,10 as; mild periodontitis $=1$ to 2 millimeters of clinical attachment loss (CAL), Moderate periodontitis $=3$ to 4 millimeter $(\mathrm{CAL})$ and Severe periodontitis $=5$ millimeter or more (CAL).

Oral Examination: The dental diagram of full mouth was utilized and every tooth was examined for each tooth position. The dental plaque was graded as no plaque $=0$, whenever required after probing over the surface of the tooth, and apparent plaque $=1$, modified plaque index of Silness and Löe. The clinical probing depth (PD) was determined longitudinal to parallel axis of tooth, from free gingival margins to the base of periodontal pocket, namely to the periodontal probe's tip. CAL is described as the distance between periodontal probe's tip and cemento-enamel junction (CEJ). By deducting these values from PD, the distance between CEJ and free gingival margins was determined and CAL was evaluated. It was deemed as a sign of gingival recession if there was receded gingival margin and revealed $C E J$, and a negative value was documented and added to PD. CAL and PD were measured in millimeters and the closest millimeters was registered. Bleeding on probing (BOP) was reported as zero "0" if no bleeding was found and one "1" when bleeding happened within 15 seconds after probing. For all parameters of every patient, average values were determined. All the data was recorded in the study proforma.

Data Analysis: Statistical analysis of data was performed by SPSS version 20.0 Description statistics were calculated including percentage and frequency for gender, child Pugh classification and severity of periodontitis. Mean $\pm S D$ (standard deviation) were calculated for numerical data. Effect modifiers were specified like age, gender; to assess their effect on outcome variable post stratification chi-square test was applied and $p$ value $<0.05$ was considered as significant.

\section{RESULTS}

Total 100 cirrhosis patients were studied, patients mean age was $46.10 \pm 9.01$ years and average of disease duration was $2.10 \pm 1.7$ years. Males were most common $62.0 \%$ and females were $38.0 \%$. According to child Pugh classification $52.0 \%$ patients were seen class III, followed by $25.0 \%$ had class II and remaining were presented with class I. Table 1

Plaque was seen almost in all cases $98.0 \%$. However, 33.0\% had mild to Moderate gingival inflammation, $28.0 \%$ had Mild to Moderate gingival inflammation and $36.0 \%$ patients seen with sever gingivitis tends to bleed and ulcerate. Table 2

According to the periodontal index most of the cases had moderate and severe periodontitis $36.0 \%$ and $35.0 \%$ respectively, $26.0 \%$ had mild periodontitis, while only $03.0 \%$ patients had no periodontitis. Figure 1

Moderate and severe periodontitis were significantly high in patients having age more than 40 years $(p=0.001)$. Among females moderate and severe periodontitis was higher as compared to males $(p=0.001)$. Moderate to severe periodontitis was significantly associated with child Pugh class II and III, $(p=0.001)$. There was no significant association between severity of periodontitis and duration of cirrhosis. Table 3 
Table 1: Demographic statistics of the patients $n=100$

\begin{tabular}{|l|c|c|c|}
\hline Variables & \multicolumn{2}{|c|}{ Statistics } \\
\hline Age & (mean \pm SD) & \multicolumn{2}{|c|}{$46.10 \pm 9.01$ years } \\
\hline \multirow{4}{*}{ Gender } & Male & 62 & $62.0 \%$ \\
\cline { 2 - 4 } & Female & 38 & $38.0 \%$ \\
\cline { 2 - 4 } & Total & 100 & $100.0 \%$ \\
\hline Duration of disease & (mean $\pm S D)$ & $3.10 \pm 1.7$ years \\
\hline \multirow{4}{*}{ Child Pugh classification } & Class-A & 25 & $25.0 \%$ \\
\cline { 2 - 4 } & Class-B & 23 & $23.0 \%$ \\
\cline { 2 - 4 } & Class-C & 52 & $52.0 \%$ \\
\cline { 2 - 4 } & Total & 100 & $100.0 \%$ \\
\hline
\end{tabular}

Table 2: Demographic statistics of the patients $n=100$

\begin{tabular}{|c|l|c|c|}
\hline \multicolumn{2}{|c|}{ Variables } & Frequency & Percent \\
\hline \multirow{7}{*}{ Plaque } & Present & 98 & $98.0 \%$ \\
\cline { 2 - 4 } & Absent & 02 & $02.0 \%$ \\
\hline \multirow{3}{*}{ Gingivitis } & No signs of inflammation & 03 & $03.0 \%$ \\
\cline { 2 - 4 } & $\begin{array}{l}\text { Mild to Moderate gingival } \\
\text { inflammation, not around tooth }\end{array}$ & 33 & $33.0 \%$ \\
\cline { 2 - 4 } & $\begin{array}{l}\text { Mild to Moderate gingival } \\
\text { inflammation around tooth }\end{array}$ & 28 & $28.0 \%$ \\
\cline { 2 - 4 } & $\begin{array}{l}\text { Sever gingivitis tend to bleed } \\
\text { and ulcerate }\end{array}$ & 36 & $36.0 \%$ \\
\hline
\end{tabular}

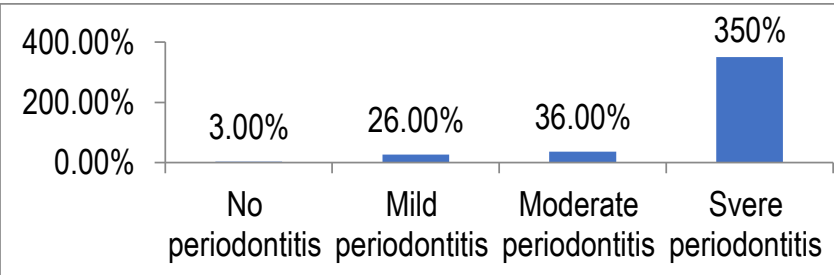

Figure 1: Patients distribution according to periodontal index $n=100$

Table 3: Periodontal index according to age, gender and severity of cirrhosis $n=100$

\begin{tabular}{|c|c|c|c|c|c|c|}
\hline \multirow{2}{*}{\multicolumn{2}{|c|}{ Variables }} & \multicolumn{4}{|c|}{ Periodontal index } & \multirow{2}{*}{$\begin{array}{c}p- \\
\text { value }\end{array}$} \\
\hline & & No & Mild & Moderate & Severe & \\
\hline \multirow{3}{*}{ Age } & 18-40 Years & 1 & 23 & 10 & 9 & \multirow{3}{*}{0.001} \\
\hline & 41-60 Years & 1 & 2 & 24 & 23 & \\
\hline & $>60$ Years & 1 & 1 & 2 & 3 & \\
\hline \multirow{2}{*}{ Gender } & Male & 1 & 26 & 15 & 20 & \multirow{2}{*}{0.001} \\
\hline & Female & 2 & 0 & 21 & 15 & \\
\hline \multirow{3}{*}{$\begin{array}{l}\text { Child Pugh } \\
\text { classification }\end{array}$} & Class-A & 1 & 24 & 0 & 0 & \multirow{3}{*}{0.001} \\
\hline & Class-B & 0 & 1 & 14 & 8 & \\
\hline & Class-C & 2 & 1 & 22 & 27 & \\
\hline \multirow{3}{*}{$\begin{array}{l}\text { Duration of } \\
\text { cirrhosis }\end{array}$} & $1-3$ years & 2 & 23 & 31 & 32 & \multirow{3}{*}{0.526} \\
\hline & $4-5$ years & 1 & 2 & 5 & 3 & \\
\hline & $>5$ years & 0 & 1 & 0 & 0 & \\
\hline
\end{tabular}

DISCUSSION

Different systemic disorders, such as liver cirrhosis, can be correlated with periodontal condition, which is a cause of chronic and subclinical infection. 2 Periodontal and persistent hepatic conditions have a two-directional adverse influence upon one another. This is due to the infectious nature of these two conditions and the essential hepatic function in the body in bacterial elimination. ${ }^{11,12}$

Serum cytokine is elevated due to hepatic dysfunction among cirrhotic patients. This may be involved in the detrimental phase of periodontal condition, likely by activation of the metalloproteinase and collagen function. ${ }^{12}$ In this study patients mean age was $46.10 \pm 9.01$ years and average of disease duration was $2.10 \pm 1.7$ years. Males were most common $62.0 \%$ and females were $38.0 \%$. Similarly Costa FO et al ${ }^{13}$ reported that out of 294 cases, males were 224 and females were 70 , with mean age of $49.3 \pm 6.9$ years. However, Ladegaard Grønkjær $L$ et al ${ }^{14}$ reported a mean age of 61 years (age ranging from 21 to 87 years) and males were $120(66 \%)$. In this study $33.0 \%$ had mild to Moderate gingival inflammation, $28.0 \%$ had Mild to Moderate gingival inflammation and $36.0 \%$ patients seen with sever gingivitis tends to bleed and ulcerate. In the study of Olczak-Kowalczyk $D$ et al ${ }^{15}$ reported that in patients struggling with hepatic disease, more serious reports of gingivitis as well as a higher incidence of oral lesions have been evident.

In this study periodontitis was significantly predominant among patients of cirrhosis and most of the cases had moderate and severe periodontitis $36.0 \%$ and $35.0 \%$ respectively, $26.0 \%$ had mild periodontitis, while only $03.0 \%$ patients had no periodontitis. Similarly Costa FO et al ${ }^{13}$ stated that there is a high incidence of periodontal disease was noted among cases $(62.2 \%)$ than controls (41.8\%). On other hand a systemic review stated that In 4 studies, the recorded incidence of periodontitis among patients with cirrhosis varied between $25.0 \%$ and $68.75 \%$, and apical periodontitis was observed among $49 \%$ to $79 \%$ of cases. $^{2}$ growing studies showed that periodontal disease may lead to the development of hepatic diseases like NALFD, cirrhosis and HCC, and also hepatic transplantations. ${ }^{16}$ Though, Grønkjær LL et al ${ }^{1}$ recorded that periodontitis was server in the vast majority of cases (46\%) and moderate in $39 \%$ of cases.

In this study moderate and severe periodontitis were significantly high in patients having age more than 40 years, female gender and having child Pugh class II and III, ( $p=0.001)$. Poor dental health can be caused by several variables, including age, educational status, depression, cognitive function, poor motivation, and medication usage. Several studies have studied the length of cirrhosis in periodontitis. 17,2 People diagnosed to have cirrhosis for $>3$ years of duration have experienced more periodontal condition symptoms than those $<3$ years of disease duration . ${ }^{2}$ This suggests that with the progression of cirrhosis, the deterioration of periodontal disorders is associated with lack of oral health. Yet more research is, though, required to determine the correlation between the periodontitis and length of cirrhosis. 


\section{CONCLUSION}

In the observation of this study the periodontitis rate was higher in patients of cirrhosis and it was significantly linked to child Pugh class II and III. During treatment dentists opinion should be taken to assess the oral health status and maintained among patients of cirrhosis.

\section{LIMITATIONS}

There were no significant limitations.

\section{SUGGESTIONS / RECOMMENDATIONS}

Factors linked to periodontal disease should be explored in cirrhotic patients to assess the link between causes and effects, the differences between cirrhosis etiology and duration, oral health practice and the role of comorbidities.

\section{CONFLICT OF INTEREST / DISCLOSURE}

There is no conflict of interests.

\section{ACKNOWLEDGEMENTS}

We acknowledge and thank to our residents, friends and seniors, for their continuous support and guidelines.

\section{REFERENCES}

1. Grønkjær LL, Holmstrup P, Schou S, Kongstad J, Jepsen P, Vilstrup H. Periodontitis in patients with cirrhosis: a crosssectional study. BMC oral health. 2018;18(1):22.

2. Grønkjær LL. Periodontal disease and liver cirrhosis: A systematic review. SAGE Open Med. 2015;3:2050312115601122.

3. Olczak-Kowalczyk D, Krasuska-Sławińska E, Gozdowski D, Kowalczyk W, Pawłowska J. Oral mucosa lesions and gingival bleeding can indicate the progression of liver disease in children and adolescents aged two to 18 years. Acta Paediatrica. 2018;107(5):886-92.

4. Raghava KV, Shivananda H, Mundinamane D, Boloor V, Thoma B. Evaluation of Periodontal Status in Alcoholic Liver Cirrhosis Patients: A Comparative Study. J Contemp Dent Pract. 2013;14(2):179-82.

5. Nagao $Y$, Kawahigashi $Y$, Sata M. Association of Periodontal Diseases and Liver Fibrosis in Patients with HCV and/or HBV infection. Hepat Mon.2014;14(12): e23264.

6. Kowalczyk DO, Kowalczyk W, Sławińska EK, Dądalski M, Kostewicz K, Pawłowska J. Oral health and liver function in children and adolescents with cirrhosis of the liver. Prz Gastroenterol. 2014; 9(1):24-31.

7. Acharya C, Sahingur SE, Bajaj JS. Microbiota, cirrhosis, and the emerging oral-gut-liver axis. JCl Insight. 2017;2(19):e94416.

8. Mitra JK, Mantu VK, Narayan S, Mitra R. Observation of Changes in Liverfunction Tests and Oral Manifestations in Cirrosis of Liver. International Journal of Contemporary Medical Research. 2016;3(4):1080-4.

9. Armitage GC. Periodontal Diagnoses and classification of periodontal diseases. Periodontology 2000. 2004;34:9-21

10. Kazi MM, Bharadwaj R, Bhat K, Happy D. Association of Herpes Viruses with Mild, Moderate and Severe Chronic Periodontitis. J Clin Diagn Res. 2015;9(7):5-8.
11. Hassan E, Ahmed AR, Eman M, Mostafa E, Sameh AM, Ahmed ES, et al. Periodontal disease as predictor of chronic liver diseases. Med J Viral Hepat. 2020;1;4(2):57-61.

12. Elhassan $A$, Peeran $S$. The Linking mechanisms between liver and periodontal diseases. EC Dental Science. 2016;4(2):758-66.

13. Costa FO, Lages EJ, Lages EM, Cota LO. Periodontitis in individuals with liver cirrhosis: A case-control study. Journal of clinical periodontology. 2019;46(10):991-8.

14. Ladegaard Grønkjær L, Holmstrup P, Schou S, Jepsen P, Vilstrup $\mathrm{H}$. Severe periodontitis and higher cirrhosis mortality. United European Gastroenterology Journal. 2018;6(1):73-80.

15. Olczak-Kowalczyk D, Krasuska-Sławińska E, Gozdowski D, Kowalczyk W, Pawłowska J. Oral mucosa lesions and gingival bleeding can indicate the progression of liver disease in children and adolescents aged two to 18 years. Acta Paediatrica. 2018;107(5):886-92.

16. Han $P$, Sun $D$, Yang J. Interaction between periodontitis and liver diseases. Biomedical reports. 2016;1;5(3):267-76

17. Raghava KV, Shivananda H, Mundinamane D, et al. Evaluation of periodontal status in alcoholic liver cirrhosis patients: a comparative study. J Contemp Dent Pract 2013;14:179-82.

\section{AUTHORSHIP CONTRIBUTION}

\begin{tabular}{|l|l|}
\hline $\begin{array}{l}\text { Dr. Almas Rahoojo } \\
\text { Assistant Professor, Bibi Aseefa Dental } \\
\text { (SMBBMU) College Larkana Pakistan }\end{array}$ & $\begin{array}{l}\text { Data collection and first } \\
\text { draft of manuscript }\end{array}$ \\
\hline $\begin{array}{l}\text { Dr. Samreen Naz } \\
\text { Assistant Professor, Oral and Maxillofacial } \\
\text { Surgery, Bhitai Dental \& Medical College } \\
\text { Mirpur-Khas Pakistan }\end{array}$ & $\begin{array}{l}\text { Contribution in } \\
\text { manuscripts writing and } \\
\text { literature review }\end{array}$ \\
\hline $\begin{array}{l}\text { Dr. Wahid Murad Dahri } \\
\text { Assistant Professor, Bibi Aseefa Dental } \\
\text { (SMBBMU) College Larkana Pakistan }\end{array}$ & $\begin{array}{l}\text { Contribution in } \\
\text { manuscripts writing and } \\
\text { literature review }\end{array}$ \\
\hline $\begin{array}{l}\text { Dr. Mansoor Ahmed Rahoojo } \\
\text { BDS Trainee, Bibi Aseefa Dental } \\
\text { (SMBBMU) College Larkana Pakistan }\end{array}$ & $\begin{array}{l}\text { Contribution in manuscript } \\
\text { writing }\end{array}$ \\
\hline $\begin{array}{l}\text { Dr. Arhama Sarwaich } \\
\text { Assistant Professor, Department of Oral } \\
\text { Pathology, Bhitai Dental \& Medical College } \\
\text { Mirpur-Khas Pakistan }\end{array}$ & $\begin{array}{l}\text { Literature review and } \\
\text { analysis }\end{array}$ \\
\hline $\begin{array}{l}\text { Dr. Sarwaich Ali Channa } \\
\text { Assistant Professor, Department of Oral } \\
\text { Pathology, Isra Dental College Hyderabad } \\
\text { Pakistan }\end{array}$ & $\begin{array}{l}\text { Data analysis and } \\
\text { formatting }\end{array}$ \\
\hline
\end{tabular}

